\title{
A Recap on Comprehensive Enhancement in Variating Solar Power Extraction under Partial Shaded Condition
}

\author{
I Rahul, R Hariharan
}

\begin{abstract}
This paper presents a thorough audit on various techniques of Photovoltaic (PV) framework under Partial Shading Conditions (PSC) which improves the yield voltage and power. Various productions report on $P V$ with respect to control upgrades and its execution. In any case, perplexity emerges while choosing an approach that performs under every climatic circumstance. In this way, a fundamental audit of PSC systems is considered, which depends on most extreme power point following (MPPT) at Standard Test Conditions (STC). These MPPT strategies can follow the Global Peak (GP) at PSC. Broad research has been investigated in this field and numerous systems have been accounted for. In this paper, a point by point portrayal and order on various procedures of PV at PSC have been made as far as control factors, structure and hardware utilized in down to earth and business applications. Incomplete Shading is a significant test in photovoltaic (PV) frameworks which influences the quality and amount of the output power. The ordinary change of condition and the diminished profitability of $P V$ Array is a significant obstruction in the brisk advancement of the sunlight based power age. A Solar PV system involves $P V$ cluster connected with an Inverter through a dc-dc converter and the yield of the Inverter is associated with the heap. In any case, expansion to PV modules, and exhibit design, control electronic converters are in like manner fundamental parts for a sun oriented based power generation. It is basic to fathom the effect of fractional concealing to make compelling and strong Photovoltaic vitality transformation structure. PV exhibit course of action, converter arrangement and MPPT control strategy are the three basic districts where the vitality extraction from $P V$ bunch can be improved under incomplete concealed condition. A point by point assessment study is coordinated among central and Micro-Inverter based PV systems and particular MPPT control techniques were pondered and considered under fractional concealed condition using MATLAB/Simulink.
\end{abstract}

Keyword : Global Peak (GP), Maximum power point following (MPPT), Photovoltaic (PV), Partial Shading Conditions (PSC), Standard Test Conditions (STC)

\section{INTRODUCTION}

Ked to the power generated due to increase in demand of numerous home appliances. Pursuit for a low cost, low maintenance and pollution free power source propels the need for renewable energy. Due to the abundance of solar energy Photovoltaic (PV) is the best substitute for standalone and grid connected modes. To track the maximum power from PV at any climatic situations, Maximum Power Point Tracking (MPPT) technique was developed. Converter topologies play

Revised Manuscript Received on October 22, 2019.

I. Rahul, Research Scholar, Department of Electrical \& Electronics Engineering, Saveetha School of Engineering, SIMATS, Chennai, India. E-Mail: immadisettyrahul@gmail.com

Dr R Hariharan, Associate Professor, Department of Electrical \& Electronics Engineering, Saveetha School of Engineering, SIMATS, Chennai, India. E-Mail: harinov22@gmail.com an important role in order to maximize the solar energy capabilities [7]. PV system Power converters for high efficiency, accurate MPPT, and voltage/current performance have to be designed. Rapid alteration in weather situations and/or Partial Shading Conditions (PSC) on PV increases the number of maxima and thus tracking for Global Peak (GP) is difficult for conventional MPPT. Several authors proposed several techniques to track the maximum power from $\mathrm{PV}$ with and without MPPT at PSC [9]. Unfortunately, limited review articles are offered in these fields that include discussions on PSC until 2003. Consequently, the complexity [10] and cost of the PV system are increased. During the partial shading condition, several maxima points are generated, which are comprised of local and global peaks. Among all these peaks the highest peak is represented as global peak, whereas others peaks are represented as local peaks. However, searching the global peak point is one of the complex tasks for MPPT control strategies. Conversely, the perceptivity of partial shading condition to a PV array is continuous. The perceptivity of partial shading [11] to a photovoltaic array can be altered with different time instances. It is illustrated that if the design pattern [13] of partial shading is identical, then the shading immensity is increased with time and the resulting maximum power of $\mathrm{PV}$ array is dropped at continuous rate. As a result, the partially shaded PV structure is always subjected to the shading immensity, when the partial shading pattern is identical. Hence, it is essential to organize a review that includes all effectual methods of $\mathrm{PV}$ refining the power at PSC before 2003 and until 2018. In this appraisal, an attempt has been made to contrast the techniques on the origin of benefits, detriments, control variables, circuit complexity, applications and implementation cost. Several review challenges have been made on MPPT at STC, but very limited attempts have been attained for MPPT at PSC. So, we are concerned about a review on PV at PSC. The solar, wind and tidal are renewable energy resources which are abundant in nature. Now-a-days these are the options for the massive power production. The demand for PV generation systems is growing in the power system distribution area. The sun irradiance is $1345 \mathrm{w} / \mathrm{m}^{\wedge} 2$ but some of it is deflected and the irradiance reaching earth is $1000 \mathrm{w} / \mathrm{m}^{\wedge} 2$.MPPT algorithm [2][8] tracks the GMPP to changing temperature and sun irradiance [12]. Since the solar installations are costly affair, many techniques were proposed in past, present such that maximum power is extracted from solar array at all times since higher returns or revenue is expected from it. Each of the past techniques has its own drawbacks, many of them failing to track GMPP quickly. 


\section{A Recap on Comprehensive Enhancement in Variating Solar Power Extraction under Partial Shaded Condition}

\section{LITERATURE REVIEW}

A) M. B. Anurag, G.S. Thrinath, S. B. Karanki, and R. Yallamili, (2016) lately sun based energy has got overall consideration in the field of sustainable power source frameworks. Among the different research pushes in sun powered PV, mainly certifiable territory is extricating utmost power from sun based PV framework. Application of Maximum Power Point Tracking (MPPT) for separating most extreme power is mainly appreciated and holds the key in creating proficient sun oriented PV framework. In this article, a cutting edge audit on different most extreme power point procedures for sun powered PV frameworks covering timeworn traditional techniques and most recent delicate registering calculations is displayed. To date basic examination on every one of the strategy as far as (1) following velocity, (2) calculation multifaceted nature, (3) Dynamic following under fractional concealing and (4) equipment execution isn't been completed. In such manner the creators have endeavored to aggregate an exhaustive survey on different sun oriented PV MPPT procedures dependent on the above criteria. Further, it is conceived that the data exhibited in this survey paper will be a significant social occasion of data for rehearsing engineers just as for new analysts.

B) A. Ziouh, and A. Abbou (2018) Unfilled hole of delayed vitality request by traditional vitality sources and assent of a dangerous atmospheric deviation as its helpless result gives a vent to look through good alternative. Expansion being used of sun oriented vitality delighted through most recent 3 decades depicts its heterogeneous rewards in the overarching vitality situation. By and by sun oriented PV framework emerges as reasonable alternative in the basic power framework time its low proficiency vitality transformation trait requires an effective power change framework. The nonlinearity of I-V (current-voltage) trademark and its modification for a various insolation and temperature esteems may empower the change in terminal voltage. This may goes astray most extreme power indicate due which the accessible greatest power conveyance to load can be contrasted. Writing of this field repeated that the uniform insolation and fractional concealing condition requests certain need of most extreme power point following. In any case through examination toward this path outfits the accessibility of a lot of such procedures; every one of them forces its very own geniuses and cones. This universal characteristic of accessible most extreme power point following (MPPT) strategies unfurls the multifaceted nature in its exact choice. To lessen such unpredictability this paper offers a condition of craft of different MPPT procedure and their exhaustive near investigation dependent on 110 standard research articles. The focal point of this paper is to offer a superior beginning and to outfit esteemed data for agents of this field.

C) K. Bouzidi, M. Chegaar, and A. Bouhemadou (2007) This paper talks about most extreme power point following (MPPT) techniques for PV framework for ordinary and incomplete concealing conditions (PSC). The chose MPPT strategies were delegated counterfeit astute, half breed, and other MPPT techniques. The examination of explores on
MPPT strategies under typical condition and PSC uncovers that scientists have focused more on concealing conditions since the most recent couple of years for the most part because of the need of intensity yield and productivity enhancements. It is accepted that the data contained in this bit of work will be of incredible use for the analysts in the field under thought.

D) N. Patel, N. Gupta, A. Kumar, and A. kumarVerma (2018) Particle swarm enhancement is a stochastic advancement, transformative and reproducing calculation got from human conduct and creature conduct too. Extraordinary property of molecule swarm streamlining is that it tends to be worked in ceaseless genuine number space straightforwardly, does not utilize angle of a target work like different calculations. Molecule swarm enhancement has couple of parameters to change, is anything but difficult to actualize and has unique normal for memory. Paper presents broad survey of writing accessible on idea, improvement and adjustment of Particle swarm advancement. This paper is organized as first idea and improvement of PSO is examined then changes with inactivity weight and tightening variable is talked about Issues identified with parameter tuning, dynamic situations, stagnation, and hybridization are likewise talked about, including a short audit of chosen takes a shot at molecule swarm streamlining, trailed by use of PSO in Solar Photo Voltaics.

E) W. Xiao, W. G. Dunford, P. R. Palmer, and A. Capel (2007) This paper gives a far reaching audit on different greatest power point following (MPPT) calculations dependent on Perturb and Observe, Incremental Conductance, Soft Computing and different procedures alongside the constant equipment execution of photovoltaic (PV) framework. In this survey, the total strategy, the execution approach and their belongings in the PV yield were talked about in detail for every calculation. Further, MPPT calculations for PV frameworks with halfway concealing condition were explored and detailed. This paper is proposed to fill in as a reasonable reference for future work in PV based power age and its related research.

F) S. Malathy, and R. Ramaprabha (2018) The most extreme power point following (MPPT) strategies for the photovoltaic (PV) control framework have been considered by the specialists in the entire world. A survey of various MPPT strategies is talked about in this paper. Initially, the fundamental techniques at uniform radiation that will be pondered are Hill-Climbing (HC), Incremental Conductance (Inc Cond), Perturbation and Observation (P\&O), Fuzzy-Logic (FL), and Neural Network (NN). Be that as it may, these current strategies have a few downsides, for example, slow following velocity, low following proficiency, which neglect to extricate greatest power at complex fractional concealing. At that point, the later MPPT techniques at fractional concealing are talked about to locate the best MPPT control procedure, for example, the molecule swarm improvement (PSO) calculation, Cuckoo Search (CS) strategy, and Fibonacci line search conspire, and so on. 
The points of interest and weaknesses of previously mentioned MPPT techniques are contrasted with locate the ideal MPPT during incomplete concealing conditions. It is envisioned that this article will be a wellspring of important data for PV experts to stay up to date with the most recent advancement in the PV control region, just as for new analysts to begin on MPPT.

G) V. R. Kolluru, R. Narne, R. K. Patjoshi, and G.T. Varghese (2017) Maximum Power Point Tracking (MPPT) is a significant worry in Photovoltaic (PV) frameworks. As PV frameworks have a mind-boggling expense of vitality it is basic that they are worked to remove the greatest conceivable power consistently. In any case, under non-uniform ecological conditions, which much of the time emerge in the open air condition, numerous MPPT systems will neglect to follow the worldwide pinnacle control. This audit paper talks about regular MPPT systems intended to work under uniform natural conditions and features why these procedures flop under non-uniform conditions. Following this, systems planned explicitly to work under non-uniform ecological conditions are broke down and thought about. Reenactment results which look at the exhibition of the basic Perturb and Observe (P\&O) technique, the Particle Swarm Optimization (PSO) and the Simulated Annealing (SA) MPPT approaches under non-uniform natural conditions are likewise introduced. The exploration introduced in this survey shows that there is no single method which can accomplish dependable worldwide MPPT with minimal effort and intricacy and be effectively adjusted to various PV frameworks.

H) M. Santolo (2017) Non-uniform irradiance essentially diminishes the power conveyed by sun oriented photovoltaic exhibits. A promising strategy for repaying these power misfortunes depends on powerfully reconfiguring the electrical associations between photovoltaic modules. This paper shows the present best in class methodologies for photovoltaic exhibit reconfiguration so as to expand the power yield under incomplete concealing and crisscross conditions. The various methodologies have been thought about as far as viability of the control.

\section{OBJECTIVES}

(1) To study Maximum Power Tracking of a Photovoltaic System Under PSC

(2) To study Performance Enhancement of Solar PV System under PSC environment

(3) To study the design of optimum Configuration of Solar PV Array which is suitable under PSC by using Particle Swarm Optimization

(4) To design PV array power output maximization under PSC using new shifted PV arrangements

\section{PROBLEM STATEMENT}

Extraction of most extreme vitality from Solar Photovoltaic Array (SPVA) under fractional concealed conditions by ideal choice of exhibit size utilizing Particle Swarm Optimization (PSO) procedure. In this paper a definite report on the yield decrease of various SPVA arrangements under incomplete concealed conditions have been done. A summed up
MATLAB M-code based programming model has been utilized for any required exhibit size, arrangement, concealing examples and number of detour diodes. Relative investigation has been done on various arrangements by testing a few concealing situations. While the quantity of concealing examples and the pace of progress are extremely low for stationary SPVA however these might be very enormous for SPVA mounted on a portable stages. This paper exhibits the appropriateness of PSO system to choose ideal arrangement for portable clusters by figuring the worldwide pinnacle (GP) of various setups and to move most extreme capacity to the heap. Fractional concealing can significantly diminish the power yield of a PV cluster just as muddle activity by making numerous pinnacles show up in the power-voltage $(\mathrm{P}-\mathrm{V})$ trademark bend. The degree of these issues depends on the concealing zone as well as and considerably more altogether on the concealing example. In this paper three new physical PV cluster courses of action are proposed to relieve halfway concealing impacts. The game plans depend on amplifying the separation between nearby PV modules inside a PV exhibit by suitably masterminding modules in various lines and segments without changing the electrical associations. A deliberate examination is performed to survey the proposed PV exhibit courses of action under various concealing examples and situations, and to contrast execution and existing designs. The new courses of action are appeared to successfully (I) redistribute concealing examples over the whole PV exhibit, (ii) limit assurance diodes control dissemination, (iii) wipe out numerous pinnacles, and (iv) augment power yield. The investigation considers concealing situations identified with cloud shape, size, transmissivity and entry over an exhibit. The new designs disentangle activity and improve execution fundamentally contrasted with the reference Series-Parallel (SP) and Total Cross Tied (TCT) setups.

\section{THEORY ON SOLAR POWER EXTRACTION}

Solar Sun based Photovoltaic cluster is framed by interfacing number of sun based photovoltaic (SPV) modules in various setups to get an ideal voltage and current levels. The serious issue in a bigger SPVA/building incorporated PV (BIPV) exhibits/versatile SPV clusters is the gathering of non uniform insolation/fractional shade. In these cases, the event of incomplete concealing is visit because of tree leaves falling over it, fowls or fledgling litters on the cluster, shade of a neighboring development and so forth. As each SPV module comprises of number of arrangement associated cells, every one of the cells are compelled to convey a similar current, despite the fact that a couple of cells under shade produce less photon current. The concealed cells may get switch one-sided, going about as burdens, emptying force out of completely lit up cells. In the event that the framework isn't appropriately ensured, problem area issue can emerge and in a few cases, the framework can be forever harmed. 


\section{A Recap on Comprehensive Enhancement in Variating Solar Power Extraction under Partial Shaded Condition}

In customary SPV frameworks, this issue decreases the general power age to a bigger level. Subsequently the SPVA establishment cost is expanded, on the grounds that the quantity of SPV modules must be expanded, and thus, SPV control age will be less alluring. This makes the investigation of fractional concealing of SPV modules a key issue. The Voltage-Power attributes of SPV module fluctuate with sun based insolation and temperature. Specialists have simple and numerical models of SPV cells for changing natural conditions. The contrast between all models is the quantity of essential parameters utilized in the computational. There are a few conditions introduced in writing to recreate the conduct of SPV cells.

Regular SPV module comprises of 36 sun powered cells associated in arrangement. SPV modules are integrated in various style to shape a cluster with required voltage and current levels. The yield intensity of a SPVA diminishes extensively, when voltage-current bends of sun oriented cells are not indistinguishable because of ruining, temperature varieties, cell harming and fractional concealing and so forth. As of late, the effect of incomplete shadowing on the vitality yield of SPV frameworks has been generally talked about. Prior to attempting to dispense with or diminish bungle impacts, a nitty gritty comprehension of their exhibition is required. Thus it is advantageous to complete the reproduction study with the assistance of a PC model which appropriately permits the consideration of jumble impacts with high exactness. In the vast majority of the investigations, the impact of halfway concealing in diminishing the yield intensity of the SPVA has been examined. Be that as it may, little consideration has been paid to the power scattered by the concealed cells influencing the exhibit life and use of the cluster for the most exceedingly awful concealed case. The unsafe impacts in fundamental arrangements and their correlation have been talked about. Normal utilization of detour diodes in anti parallel with the arrangement associated PV modules can halfway improve the power decrease because of fractional shadow. In such cases an increasingly entangled Maximum Power Point Tracking (MPPT) calculations fit to ignore nearby control maxima is required. Then again, the most extreme accessible DC power can be improved if the association of the SPV modules can be reconfigured to such an extent that boards with comparative working conditions are associated in a similar arrangement string. Moreover the parallel design ought to be overwhelming under fractional concealed conditions. Be that as it may, high yield current at low voltage in parallel design should be appropriately molded to the required level by utilizing reasonable DC-DC converter. For the design types, the summed up MATLAB projects have been created which are fit for reenacting any number of modules associated in arrangement or parallel and any sort of concealing examples. The examination study is made among the setups with detour diodes. For specific insolation and temperature various designs will be predominant. It is standard to choose an appropriate size of SPV cluster. Something else, an enormous change in SPV control in light of insolation variety brought about by concealing may prompt precariousness. Following the most extreme power point is required so as to extricate the biggest measure of intensity from a SPVA, paying little respect to

climate or burden conditions. Different MPPT techniques have been proposed and used to remove greatest power from SPVA under fluctuating air conditions and halfway concealed conditions.

\section{EXISTING SYSTEM}

The energy extraction characteristics of every converter structure are similar but under partial shaded condition the maximum power captured are strongly depends upon the converter configuration. The central and micro inverter configurations are discussed below. Central converter configuration a large single inverter is used to convert the whole DC power generated by array called as central inverter. The inverter configuration relies on the sizing of the PV array, thus sizing of array is an essential factor in Central inverter configuration. Central converters are commonly used converter in early days. In this type of configuration all the solar panels are linked to a common inverter through DC-DC boost converter integrating with MPPT control technique. The drawback of central inverter setup is size of the inverter and space required for eretion is expansive and appropriate cooling framework is required. Also it has large power loss because of shading of adjacent PV modules inside the array.

\section{PROPOSED SYSTEM}

Solar cells are the fundamental unit of PV framework that are linked in series to outline a module or panels. Solar panels are comprised of Solar cells orchestrated in way to catch sunlight and furthermore canvassed by a Glass in the best to secure the cells and furthermore to enable the sunlight to fall on PV, the glass has the property of diminishing the warmth which enhances the semiconductor to work productively.

$$
\mathrm{I}=\mathrm{N}_{\mathrm{p}} \mathrm{I}_{\mathrm{ph}}-\mathrm{N}_{\mathrm{p}} \mathrm{I}_{\mathrm{S}}\left[\exp \left(\mathrm{qV}_{\mathrm{oc}} / \mathrm{N}_{\mathrm{S}} \mathrm{K}_{\mathrm{c}} \mathrm{A}\right)-1\right]
$$

$\mathrm{Np}$ - cells in parallel

Ns - cells in series

Iph - Photocurrent

Is - saturation current

Voc - open circuit voltage

Parallel connections are done to increase the current rating that is done in module level. Mismatch in solar cell because of partial shading cause power loss as well as cause permanent damage to the cell. PV module is built by utilizing mathematical modeling by the equation 1. The Fig.1 demonstrates the Equivalent circuit diagram of PV array.

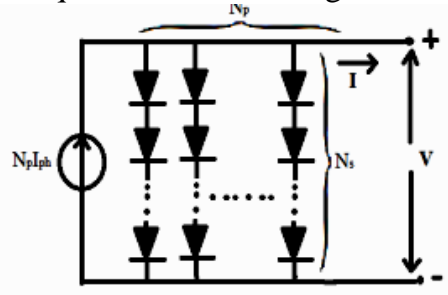

Figure 1: Equivalent circuit of PV module

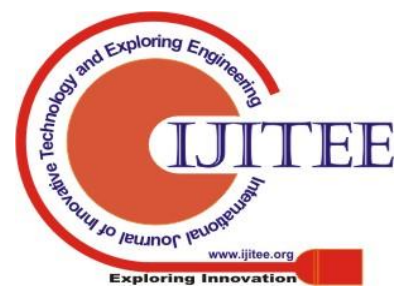




\section{APPLICATIONS}

(1) Superior solar power plants that collect the heat from the sun, which is consequently used to produce steam for powering a generator

(2) Solar energy is harnessed to drive water in remote areas

(3) Solar cookers, Solar cars, solar trams, solar buses and even satellites are also operated with the help of solar energy.

(4) Recreational vehicles and some boats may also run on solar energy.

(5) Tiny gadgets that involve little energy, such as calculators and watches, often use solar energy.

\section{METHODOLOGY}

Sensibly partial shade has great bang on larger arrays. For perceptive the practical cases, it is required to go for larger arrays with different configurations. Several S configurations have been proposed in the Fig. 2 with series, parallel, series parallel (SP) total cross tied (TCT) and bridge linked (BL) configurations. Among which Series and parallel configurations are the basic configurations and their performance has been discussed in detail. The major drawbacks of such configuration leads to decrease of current and voltage values respectively.

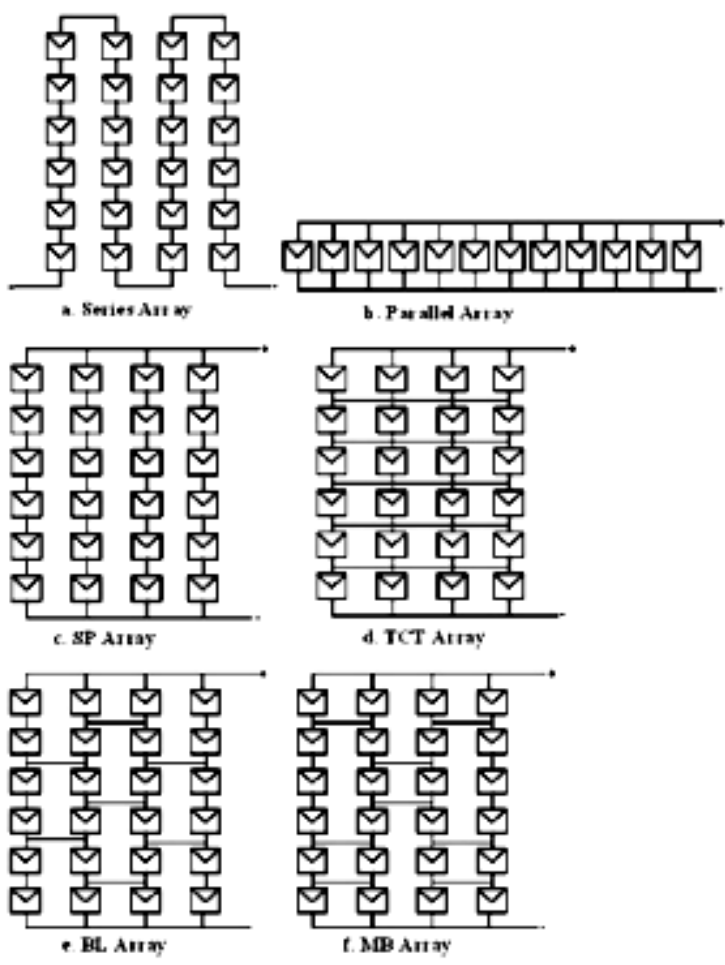

Figure 2: Schematic diagram of SPVA configurations

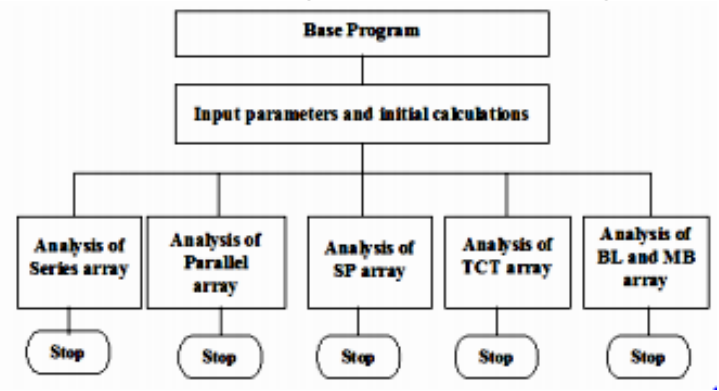

Figure 3: Architecture of the developed software
From the above discussion, it may be fulfilled that to study and understand the effects of partial shading on SPV arrays, a simple tool is not available for the purpose. Therefore, it is felt that there is a need for a flexible, interactive, and comprehensive simulation model capable to predict the PV characteristics (including multiple peaks) and output power under partially shaded conditions. Model developed by authors have been in use for the analysis.

\section{RESULTS}

\section{A) Simulink model of Central inverter}

Simulation of a Central Inverter is given in Fig.4 Here a $3 \times 3 \mathrm{PV}$ array is arranged in series, parallel connected to a common inverter called Central inverter through a boost converter by MPPT control technique. The outcome of the inverter is linked to a resistive load R through an LC filter. THD level for the outcome voltage waveform is calculated using Fast Fourier Transform (FFT) analysis.

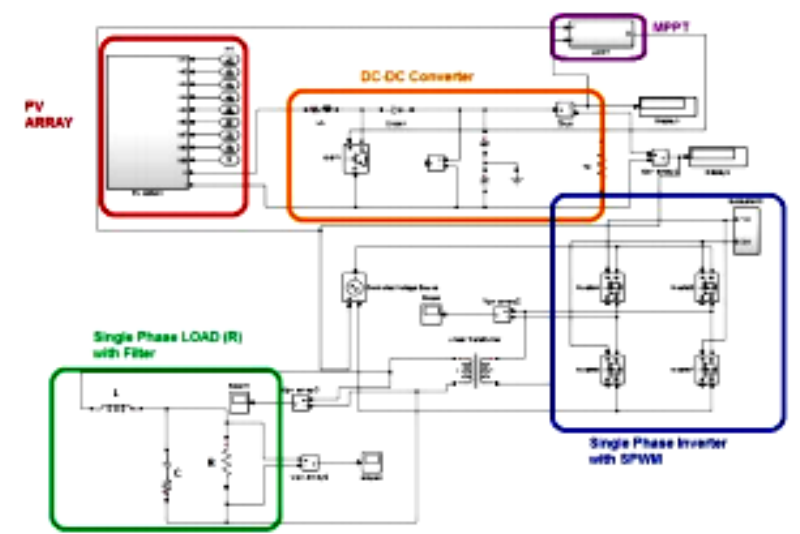

Figure 4: Simulink model of Central inverter

\section{B) Simulink model of Micro inverter}

Simulink model of Micro Inverter is given below in Fig.5 Here each PV module is linked to a separate inverter called Micro inverter through a boost converter by MPPT control technique. The output of the each inverter is connected in parallel to a resistive load $\mathrm{R}$ through an $\mathrm{LC}$ filter.

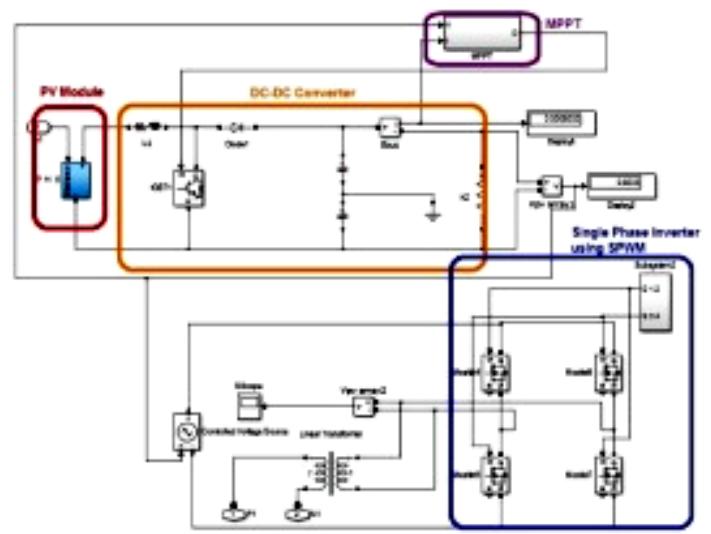

Figure 5: Simulink model of a Micro inverter configuration 


\section{A Recap on Comprehensive Enhancement in Variating Solar Power Extraction under Partial Shaded Condition}

In this way output of the nine Micro inverter are linked in parallel THD level for the output voltage waveform is determined utilizing FFT investigation.

\section{C) Output of Micro inverter}

The Fig.6 gives the THD value for output waveform of Micro inverter. Similarly THD is calculated for various Shading patterns and comparison is made between central and Micro inverter.

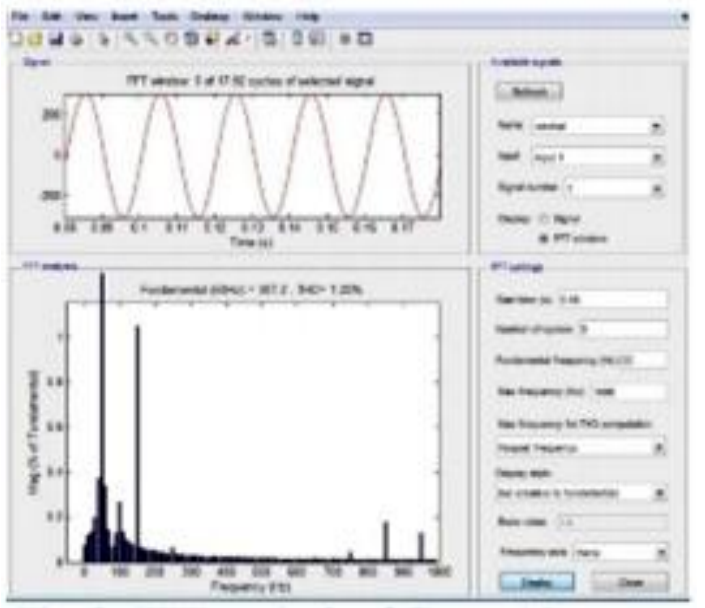

Figure 6: FFT analysis of CentralInverter

\section{THD value under different shading scenarios}

THD value obtained for Central and Micro inverter under same shading conditions for all panels i.e., same value of irradiance for all the PV panels are presented.

\section{In part concealed $P V$ modules}

PV Modules P1, P2, P3, P4, P7, P5, P9, are concealed progressively by keep up $200 \mathrm{~W} / \mathrm{m} 2$ as the Irradiance level. The underneath table VI shows the THD regard procured by FFT assessment under various Shaded condition. Miniaturized scale inverter in concealed condition and has Low transmission misfortune and high Efficiency than focal inverter. The age limit of the Plant can be extended adequately in Micro Inverter arrangement. The Power created in one board won't impact by the neighboring boards under Shading caused. In Micro-Inverter increase in broad number of PV exhibits on a very basic level grows the amount of semiconductor switches, making them cost prohibitive.

\section{D) Simulink model of MPPT control}

PV cluster is associated with a Resistive burden through Boost converter. The lift converter support the yield voltage by turning $\mathrm{ON}$ and OFF the switch, here the switch utilized is Integrated Gate Bipolar Transistor (IGBT). Yield waveform created for different irradiance examples is given beneath in Fig.7
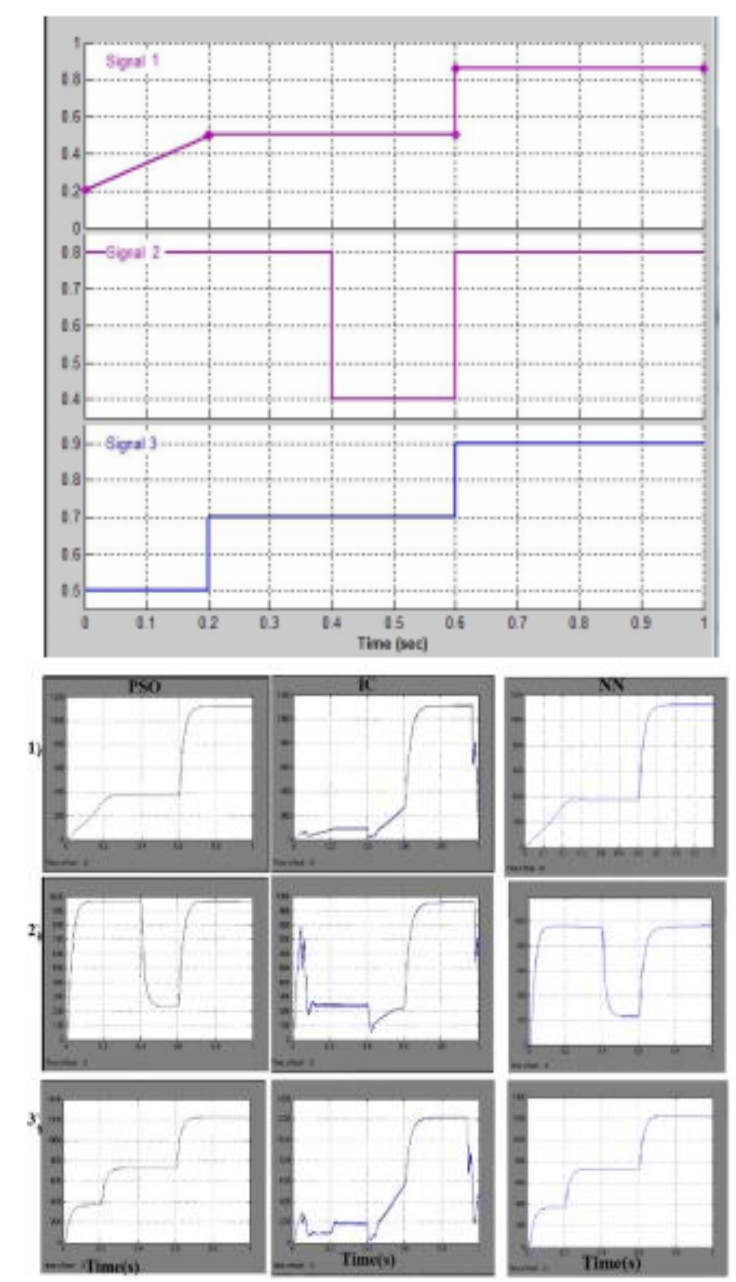

Figure 7: Different Shading patterns

\section{CONCLUSION}

India and other countries in the world want solar installations in all the states. So in coming years there is a clear targeblet it wants all the power from solar panels which is achievable more over it also adds to the environmental benefit that' is reduction of greenhouse gases, variation in ambient temperature will derate and reduce the life of the solar array. While selecting the solar panels for applications normally some margin of wattage is selected. Check the ratings with respect to temperature and ambient temperature of the site where it is installed such that deration is tackled. This will benefit designers and maintenance personnel. Secondly at night the PV systems are dead so at day with the enhanced design extra units are supplied to campus usage /to grid. And at night we can take from grid source or batteries in campus if energized.

\section{FUTURE SCOPE}

Numerous of researchers have proposed several MPPT control algorithms for PSC system. However, MPPT for PSC system is an amenable research area where many future scopes are still there. 
Therefore, various metaheuristic optimization methods for MPPT under PSC systems are proposed, many of these techniques are also considered in this paper. But various techniques are still available, which explore MPPT algorithms are Pareto multi objective optimization (PMOO), shuffled frog leaping (SFL), Artificial immune system optimization (AISO), invasive weed optimization (IWO), cuckoo search algorithm (CSA), fish optimization (FO), raindrop optimization (RO), tabu search continuous optimization (TSCO), seeker optimization algorithm (SOA)

\section{REFERENCES}

1. M. B. Anurag, G.S. Thrinath, S. B. Karanki, and R. Yallamili, "Design of ZVS based high gain DC-DC converter for PV applications", 2016 IEEE International Conference on Renewable Energy Research and Applications (ICRERA), pp. 584-589. 20-23 November 2016.

2. A. Ziouh, and A. Abbou, "Fuzzy-Super Twisting Sliding Mode MPPT Control for Three-Phase Grid-Connected PV", International Journal of Renewable Energy Research (IJRER), vol.8, no.4, pp.1812-1823, 2018.

3. K. Bouzidi, M. Chegaar, and A. Bouhemadou, "Solar cells parameters evalutaion considering the series and shunt resistance", Sol. Energy Mater. Sol. Cells, vol. 91, no. 18, pp. 1647-1651, Nov. 2007.

4. N. Patel, N. Gupta, A. Kumar, and A. kumarVerma, "Multifunctional Grid Interactive Solar Photovoltaic Systems: A Comprehensive Review", International Journal of Renewable Energy Research (IJRER), vol.8, no.4, pp.2116-2130, 2018.

5. W. Xiao, W. G. Dunford, P. R. Palmer, and A. Capel, "Regulation of photovoltaic voltage", IEEE Trans. Ind. Electron., vol. 54, no. 3, pp. 1365-1374, Jun. 2007.

6. S. Malathy, and R. Ramaprabha, "A Two-Stage Tracking Algorithm for PV Systems Subjected to Partial Shading Conditions", International Journal of Renewable Energy Research (IJRER), vol.8, no.4, pp.2249-2256, 2018.

7. V. R. Kolluru, R. Narne, R. K. Patjoshi, and G.T. Varghese, "Implementation of a novel P\&O MPPT Controller for Photovoltaic System at Standard Test Conditions", International Journal of Applied Engineering Research, vol.12, no.1,pp.624-629,2017.

8. M. Santolo, "Super twisting sliding mode control of smart-inverters grid-connected for PV applications", 2017 IEEE 6th International Conference on Renewable Energy Research and Applications (ICRERA), pp. 793- 796, 5-8 November 2017.

9. A. Safari, and S. Mekhilef, "Simulation and hardware implementation of incremental conductance MPPT with direct control method using cuk converter", IEEE Trans. Ind. Electron., vol. 58, no. 4, pp. 1154-1161, Apr. 2011.

10. V.R. Kolluru, S. S. Sarode, and R.K. Patjoshi, "Design and Implementation of an Optimized Sliding Mode Controller and Compared with a Conventional MPPT Controller for a Solar System", WSEAS Transactions on systems and control,vol.9,pp.558-565, 2014

11. M. H. Taghvaee, M. A. M. Radzi, S. M. Moosavain, H. Hizam, and M. H. Marhaban, "A current and future study on non-isolated DC-DC converters for photovoltaic applications", Renew. and Sustain. Energy Reviews, vol. 17, no.1, pp. 216-227, Jan. 2013.

12. Y.E. Eldahab, N.H. Saad, and A. Zekry, "Enhancing the tracking techniques for the global maximum power point under partial shading conditions", Renewable and Sustainable Energy Reviews, vol. 73, pp.1173-1183, 2017.

13. A. Kajihara, and T. Harakawa, "On considerations of equivalent model about PV cell under partial shading”, In Proc. Japan, Ind. App. Soc. Conf., vol. 1, no. 71, pp. 289-292, 2005.

14. A. Badis, M. H. Boujmil, and M. N. Mansouri, "A comparison of global MPPT techniques for partially shaded grid-connected photovoltaic system", International Journal of Renewable Energy Research (IJRER), vol.8, no. 3, pp.1442-1453, 2018.

15. S. Gautam, D. B. Raut, P. Neupane, D. P. Ghale, and R. Dhakal, 'Maximum power point tracker with solar prioritizer in photovoltaic application”, 2016 IEEE International Conference on Renewable Energy Research and Applications (ICRERA), pp. 1051-1054, 20-23 November 2016.

16. L. EL Iysaouy, M. Lahbabi, and A. Oumnad, "Enhancing the Performances of PV Array Configurations Under Partially Shaded Conditions: A Comparative Study",International Journal of Renewable Energy Research (IJRER), vol. 8, no.3, pp.1779-1790, 2018.
17. A. Woyte, J. Nijs, and R. Belmans, "Partial shadowing of photovoltaic arrays with different system configurations literature review and field test results", Solar Energy, vol. 74, no. 3, pp. 217-233, Jul. 2003.

18. W. Hermann, W. Wiesner, and W. Vaaben, "Hot spot investigations on PV modules - new concepts for a test standard and consequences for module design with respect to bypass diodes", IEEE Photovoltaic specialists conf., pp. 1129-1132, 1997.

19. G. Li, Y. Jin, M. W. Akram, X. Chen, and J. Ji, "Application of bio-inspired algorithms in maximum power point tracking for PV systems under partial shading conditions-A review", Renewable and Sustainable Energy Reviews, Vol.81, pp.840-873, 2018.

20. H. Chaieb, and A. Sakly, "A novel MPPT method for photovoltaic application under partial shaded conditions", Solar Energy, vol.159, pp.291-299, 2018.

21. H. Rezk, A. Fathy, and A. Y. Abdelaziz, "A comparison of different global MPPT techniques based on metaheuristic algorithms for photovoltaic system subjected to partial shading conditions", Renewable and Sustainable Energy Reviews, vol.74, pp.377-386, 2017.

22. S. Silvestre, A. Boronat, and A. Chouder, "Study of bypass diodes configuration on PV modules", Appl. Energy, vol. 86, no. 9, pp. 1632-1640, Sep. 2009

23. N. D. Benavides, and P. L. Chapman, "Modelling the effect of voltage ripple on the power output of photovoltaic modules", IEEE Trans. Ind Electron., vol. 55, no. 7, pp. 2638-2643, Jul. 2008.

24. P. Rodrigo, D. F. Fernandez, F. Almonacid, and P. J. P. Higueras, "A simple accurate model for the calculation of shading power losses in photovoltaic generators", Solar Energy, vol. 93, no. 1, pp. 322-333, Jul. 2013.

25. M. Seyedmahmoudian, S. Mekhilef, R. Rahmani, R. Yusof, and E. T. Renani, "Analytical modeling of partially shaded photovoltaic systems", Energies, vol. 6, no. 1, pp. 128-144, Jan. 2013. 